\title{
Streptozotocin-induced diabetes can be reversed by hepatic oval cell activation through hepatic transdifferentiation and pancreatic islet regeneration
}

\author{
Seungbum Kim ${ }^{1}$, Jun-Seop Shin ${ }^{1}$, Hyun-Jung Kim ${ }^{1}$, Robert C Fisher ${ }^{2}$, Mi-Ji Lee ${ }^{1}$ and Chan-Wha Kim ${ }^{1}$
}

Hepatic oval cells have shown the potential to transdifferentiate into insulin-producing cells when cultured with high glucose concentrations. However, it remains unknown whether the oval cells can contribute to insulin production in diabetic mice. In this study, our aim was to investigate the response of activated hepatic oval cells to hyperglycemic conditions. C57BL/6 mice were fed a diet containing 0.1\% 3,5-diethoxycarbonyl-1,4-dihydrocollidine (DDC) for 4 weeks to activate the hepatic oval cell population before inducing hyperglycemia with streptozotocin (STZ). Despite the initial hyperglycemia $(341 \pm 15 \mathrm{mg} / \mathrm{dl})$, the blood glucose levels of DDC-STZ-treated mice were significantly improved within 6 weeks $(185 \pm 12 \mathrm{mg} / \mathrm{dl})$. During the initial hyperglycemic stage, DDC-STZ-treated livers expressed pancreatic developmental, endocrine and exocrine genes. Hepatic insulin production was confirmed by immunohistochemistry and ELISA. These results suggested that transdifferentiated hepatic oval cell population contributed to the amelioration of hyperglycemia. We additionally determined that DDC-STZ-treated pancreata played a critical role in complete reversal of hyperglycemia as evidenced by extensive $\beta$-cell regeneration and increase of pancreatic insulin content after STZ treatment, which is rarely observed in other adult STZ models. Reversal of hyperglycemia in this model seems to be accomplished by biphasic insulin augmentation, first by hepatic transdifferentiation, and followed by endogenous $\beta$-cell regeneration in the pancreas. The DDC-STZ treatment provides a novel injury model for better understanding of the functional behavior of hepatic and pancreatic stem/progenitor cell population under hyperglycemic condition, which may yield critical information for developing $\beta$-cell-based therapies to treat diabetes.

Laboratory Investigation (2007) 87, 702-712; doi:10.1038/labinvest.3700561; published online 7 May 2007

KEYWORDS: diabetes; hepatic oval cell; islet neogenesis; pancreas regeneration; stem cell; transdifferentiation

The pancreatic endocrine compartment is composed of the islets of Langerhans, which are clusters of four cell types that synthesize insulin $(\beta$-cells), glucagon $(\alpha$-cells), somatostatin $(\delta$-cells) and pancreatic polypeptide (pp-cells). In mature rodent pancreatic islets, $\beta$-cells are located in the core, whereas $\alpha$-, $\delta$ - and pp-cells are in the rim. The pancreatic $\beta$ cell possesses the ability to respond to minor increases in the plasma glucose levels, thereby keeping the blood glucose level within a very narrow range. ${ }^{1}$ Progressive destruction of pancreatic $\beta$-cell leading to decreased insulin production and subsequent hyperglycemia is observed in all forms of diabetes mellitus. Therefore, the number of functional $\beta$-cells in the pancreas is of decisive importance in the development and progress of the disease. To date, the most effective long-term treatment of diabetes is islet transplantation, a procedure known as the Edmonton protocol. ${ }^{2}$ However, there is currently a severe shortage of pancreas donors, creating a need for new strategies to generate pancreatic $\beta$-cells either in vitro or in vivo. Pancreatic stem/progenitor cells should be considered as the primary sources to generate insulin-producing cells. However, to date, no adult pancreatic stem cells have been fully characterized, even though several candidate cell populations have been identified including pancreatic ductderived stem cells ${ }^{3,4}$ and nestin-positive islet-derived progenitor cells, ${ }^{5}$ which may play important roles in pancreas regeneration.

Animals treated with diabetogenic $\beta$-cell toxins (eg streptozotocin (STZ), alloxan) show very limited ability to regenerate $\beta$-cells and eventually fail to restore normal glucose level due to the low mitotic activity of pancreatic islet and

${ }^{1}$ School of Life Sciences and Biotechnology, Korea University, Seoul, Korea and ${ }^{2}$ Program in Stem Cell Biology and Regenerative Medicine, Department of Molecular Genetics and Microbiology, University of Florida, Gainesville, FL, USA

Correspondence: Dr C-W Kim, PhD, Department of Biotechnology, School of Life Sciences and Biotechnology, Korea University, 5-1 Anam-dong, Sungbuk-gu, Seoul 136-701, Korea. E-mail: cwkim@korea.ac.kr

Received 10 December 2006; revised 02 March 2007; accepted 10 March 2007 
toxic effect of high glucose to the remaining $\beta$-cell. ${ }^{6,7} \mathrm{Al}-$ though insulin is primarily produced in the pancreatic islets, a previous study has revealed the existence of extrapancreatic insulin-producing cells in multiple organs such as liver, spleen, bone marrow and adipose in hyperglycemic conditions. ${ }^{8}$ However, the newly emerged insulin-producing cells in the pancreas and other organs are not sufficient in number as well as in insulin production ability to reverse the diabetic condition. ${ }^{9}$ Although hyperglycemia is detrimental to islet $\beta$ cells, high glucose is a very efficient signal in vitro for differentiation of stem cells into insulin-producing cells. ${ }^{10,11} \mathrm{We}$ hypothesized that if enough stem cells were activated before the diabetic induction, hyperglycemia could be ameliorated by these transdifferentiating stem cells. Toward this goal, we focused on the liver for stem cell activation because, unlike the pancreas, there are several ways to increase hepatic oval cell population, which is thought to be the primary multipotent stem cell population in the liver. ${ }^{12,13}$ Furthermore, hepatic oval cells are thought to have the potential to transdifferentiate into pancreatic endocrine cells, as both the liver and the pancreas originate from appendages of the upper primitive foregut endoderm. ${ }^{14}$ It has been suggested that the late separation of the liver and the pancreas during organogenesis in primitive ventral endoderm might have left both tissues with pluripotent cells that are capable of giving rise to both hepatic and pancreatic lineage. ${ }^{15,16}$ Indeed, Yang et $a l^{10}$ have shown in an in vitro experiment that hepatic oval cells, when cultured in high glucose media, can differentiate into pancreatic endocrine cells which support this hypothesis.

In this study, we determined the transdifferentiation ability of hepatic oval cells under hyperglycemic conditions by incorporating 3,5-diethoxycarbonyl-1,4-dihydrocollidine (DDC) in a standard chow, which has been proved to be an effective inducer for mouse oval cell proliferation, ${ }^{13}$ followed by STZ injection for hyperglycemia induction. Here, we demonstrated that the oval cell-activated livers contain insulinproducing cells, which contributed to the amelioration of hyperglycemia. In addition, DDC-treated pancreas possessed hepatocyte like cells and pancreatic precursor cells in the main and common ducts, which showed a distinctive ability to repopulate $\beta$-cells after STZ treatment. Our results suggest that DDC-STZ treatment can trigger the extensive pancreatic $\beta$-cell regeneration to reverse the STZ-induced hyperglycemia. This novel in vivo model can provide a reproducible experimental system to investigate adult $\beta$-cell differentiation and islet regeneration.

\section{MATERIALS AND METHODS Animals}

Male C57BL/6 mice were kept in a humidity -and temperature-controlled chamber under a 12-h light/dark cycle. Mice were fed on a standard diet and water ad libitum before the experiment. All animals were cared in compliance with the institutional guidelines.

\section{3,5-Diethoxycarbonyl-1,4-Dihydrocollidine and Streptozotocin Treatment}

At 5 weeks of age, a diet containing 0.1\% DDC (Bioserve, Frenchtown, NJ, USA) was fed to mice for 4 weeks. A standard diet was given to control group. At 2 days after shifting to the standard diet, hyperglycemia was induced by a single intraperitoneal injection of STZ (Sigma, St Louis, MO, USA) at a dose of $150 \mathrm{mg} / \mathrm{kg}$ after overnight fasting for both DDCtreated and normal mice. Blood was drawn from tail vein and non-fasting blood glucose levels were determined with a blood glucose meter (Lifescan Inc., Milpitas, CA, USA) at a consistent time of the day. The STZ-induced diabetic mice, which had non-fasting glucose levels of $>250 \mathrm{mg} / \mathrm{dl}$ for 14 consecutive days, were selected for further experiments.

\section{RNA Isolation and RT-PCR Analysis}

DDC-treated mice were killed at 5, 15, 30, 60, 120 days postSTZ injection and the livers were removed for further analysis. Total RNA was extracted as described previously. ${ }^{17}$ Oligonucleotide sequences and PCR conditions are listed in an online Supplementary table. The PCR products were analyzed on a $1.8 \%$ agarose gel containing ethidium bromide. Key PCR products of genes related to pancreatic development were confirmed by sequence analysis and a separate PCR reaction without reverse transcriptase was carried out to ensure the results were not from genomic DNA contamination.

\section{Immunohistochemistry}

Organs were removed and fixed in 10\% buffered formalin. For detection of pancreatic antigens, guinea pig anti-insulin, rabbit anti-glucagon, rabbit anti-somatostatin (Dako) and guinea pig anti-proinsulin (Progen, Heidelberg, Germany) were used as recommended by the manufacturers. The sections were further incubated for $1 \mathrm{~h}$ with fluorescent secondary antibodies (Jackson Immunoresearch) diluted in PBS at room temperature. Peroxidase- or phosphatase-linked polymers conjugated to goat anti-rabbit immunoglobulins (Envision plus kit or Envision doublestain kit; Dako) were used to visualize the pancreatic endocrine hormones according to the manufacturer's specification. Slides were counterstained by hematoxylin or nuclear fast red (Dako).

\section{Morphometric Analysis and Statistics}

To locate $\beta$-cells in the tissue, each pancreas was sectioned throughout the length to avoid regional variation. All slides were randomized and relabeled before analysis. The relative $\beta$-cell volume was determined in sections immunostained for insulin by the random point sampling method described by Guz et $a l^{9}$ with modifications. Briefly, the density of insulinpositive area was calculated from 10 systematically selected fields for each slide under light microscopy. Each field $\left(0.16 \mathrm{~mm}^{2}\right)$ was transferred to digital image by charge-coupled device camera, divided into 720 point grid and the relative volume of $\beta$-cells per tissue was estimated according to 
the formula: $F=h / n$ in which $h$ was the number of 'hits' over $\beta$-cells and $n$ the number of points over the pancreatic tissue. Measurement of the area covered $>16 \mathrm{~mm}^{2}$ from at least three individual animals per each time period. The mean cross-sectional diameter $(\mu \mathrm{m})$ of individual insulin-positive cluster in pancreas was measured in fixed interval sections from at least three animals per each time period as described previously. ${ }^{18}$ More than 200 single insulin-positive cells were counted for Figure 4a and categorized as ductal and parenchymal single cells in the same slides. For the measurement of insulin-glucagon- and insulin-somatostatin-positive cells in the pancreas, sections were doublestained with fluorescein isothiocyanate (FITC) and rhodamine as described above, counterstained with 4,6-diamidino-2-phenylindole, and each antigen-positive cells in $>50$ islets per each time period were counted. Cells that coexpressed insulin and somatostatin in hyperglycemic stage were considered extraneous to each other.

For statistical analysis, SPSS (Release 10.0.7, SPSS Inc., Chicago, IL, USA) and SigmaPlot (Version 8.0, SPSS Inc.) were used. Differences among groups were determined with one-way analysis of variance or pairwise comparisons when appropriate. Post hoc analysis for differences between specific groups was performed with Tukey's Studentized range test. Differences were considered significant at $P<0.05$.

\section{Enzyme-Linked Immunosorbent Assay of Insulin}

The insulin content of whole-wet livers and pancreata were measured by ELISA. Liquid nitrogen snap-frozen tissues of each age were immediately homogenized in $0.18 \mathrm{~N} \mathrm{HCl}, 35 \%$ ethanol. The homogenates were extracted overnight at $4^{\circ} \mathrm{C}$ with continuous stirring and then centrifuged. Supernatants were neutralized by $0.18 \mathrm{~N} \mathrm{NaOH}$, supplemented by protease inhibitor cocktail (Sigma), and stored at $-70^{\circ} \mathrm{C}$ until assayed. Hepatic and pancreatic immunoreactive insulin were determined using mouse ELISA kit (Shibayagi, Gunma, Japan) according to the manufacturer's protocol.

\section{Intraperitoneal Glucose-Tolerance Test}

To examine effective insulin secretion in response to high glucose challenge in DDC-STZ-treated mice, glucose-tolerance tests were carried out at 5, 15, 30, 45, 60 days post-STZ injection. All animals were fasted for $14 \mathrm{~h}$ and received an intraperitoneal glucose load of $1.5 \mathrm{~g} / \mathrm{kg}$ body weight diluted in PBS. Blood glucose levels were measured at 0, 30, 60, 120, $180,240 \mathrm{~min}$ after the glucose injection by a blood glucose meter.

\section{RESULTS}

\section{Histology of DDC-Treated Livers and Pancreata}

In DDC-treated livers, we observed the abnormal increase of non-parenchymal cells, primitive ductular structures with poorly defined lumen and heme breakdown debris (Figure 1a and $\mathrm{b}$ ), which are characteristics of the DDC model. ${ }^{13,19}$ Heme breakdown debris and abrupt ductal cell proliferation were observed with less frequency in DDC-treated pancreata (Figure 1d and e). Previous studies have suggested that the murine pancreas contained pancreatic oval cells and hepatocyte under certain stimuli. ${ }^{20,21}$ Histological observation revealed basal precursor cells and hepatocyte-like cells in DDC-treated pancreata, which were primarily localized to the main and common ducts as suggested by Bonner-Weir et $\mathrm{al}^{22}$ Whether these basal cells observed in pancreatic ducts are equivalent to the oval cells in the liver remains to be determined, but under hyperglycemic condition, they expressed insulin and somatostatin (Figure 1f).

\section{Blood Glucose Levels of DDC-STZ-Treated Mice}

Both DDC-STZ-treated and STZ-treated groups showed frank hyperglycemia within $48 \mathrm{~h}$ (blood glucose level $>250 \mathrm{mg} / \mathrm{dl}$ ). For most of the DDC-STZ-treated mice, the hyperglycemia was observed for more than 14 days (Figure 1g; average blood glucose level of the first 2 weeks, $321 \pm 8 \mathrm{mg} / \mathrm{dl}$ ). DDC-STZ group showed reversal of hyperglycemia starting at 15 days post-STZ injection and the average blood glucose level of 40 days post-STZ injection $(185 \pm 12 \mathrm{mg} / \mathrm{dl})$ was not significantly different from normal blood glucose level $(P=0.7,163 \pm 12 \mathrm{mg} / \mathrm{dl})$. We confirmed that reversal of hyperglycemia did not occur in mice fed with DDC diet for 1-7 days, which indicates that DDC itself is not an inhibitor of STZ effects (data not shown).

Two additional experiments were carried out to exclude the potentially confounding effects of STZ on DDC-treated mice. First, we confirmed that reversal of hyperglycemia did not occur in mice fed with the DDC diet for 1-7 days, which indicates that DDC itself is not an inhibitor of STZ effects and that sufficient hepatic oval cell activation is necessary for the reversal of hyperglycemia. Next, we administrated STZ first $(150 \mathrm{mg} / \mathrm{kg})$, confirmed the hyperglycemia (blood glucose level $>250 \mathrm{mg} / \mathrm{dl}$ ) and the mice were put on DDC diet for 4 weeks $(n=15)$. However, $66.7 \%$ of mice died within 2 weeks of DDC treatment and only $13.3 \%$ maintained normoglycemia $(141 \pm 12 \mathrm{mg} / \mathrm{dl})$, when the diet was shifted to normal. Histological analysis showed that hepatic oval cells were not efficiently activated in the hyperglycemic mice (data not shown).

\section{Pancreatic Genes Activation and Insulin Production in Oval Cell-Activated Livers}

Next, we examined the expression of pancreatic transcripts associated with pancreas organogenesis in the livers of DDCSTZ mice by RT-PCR. We observed that pancreas endocrine hormones, major pancreatic development factors and pancreatic exocrine enzymes were transcribed in the liver (Figure 2a). Most pancreatic genes were expressed by 5 days and continued to be expressed up to 15 days post-STZ injection, which indicate that hepatic transdifferentiation starts very early during the hyperglycemic stage. The hyperglycemia seemed to play a critical role in the development of insulinproducing cells in the DDC-STZ liver as some transcripts 

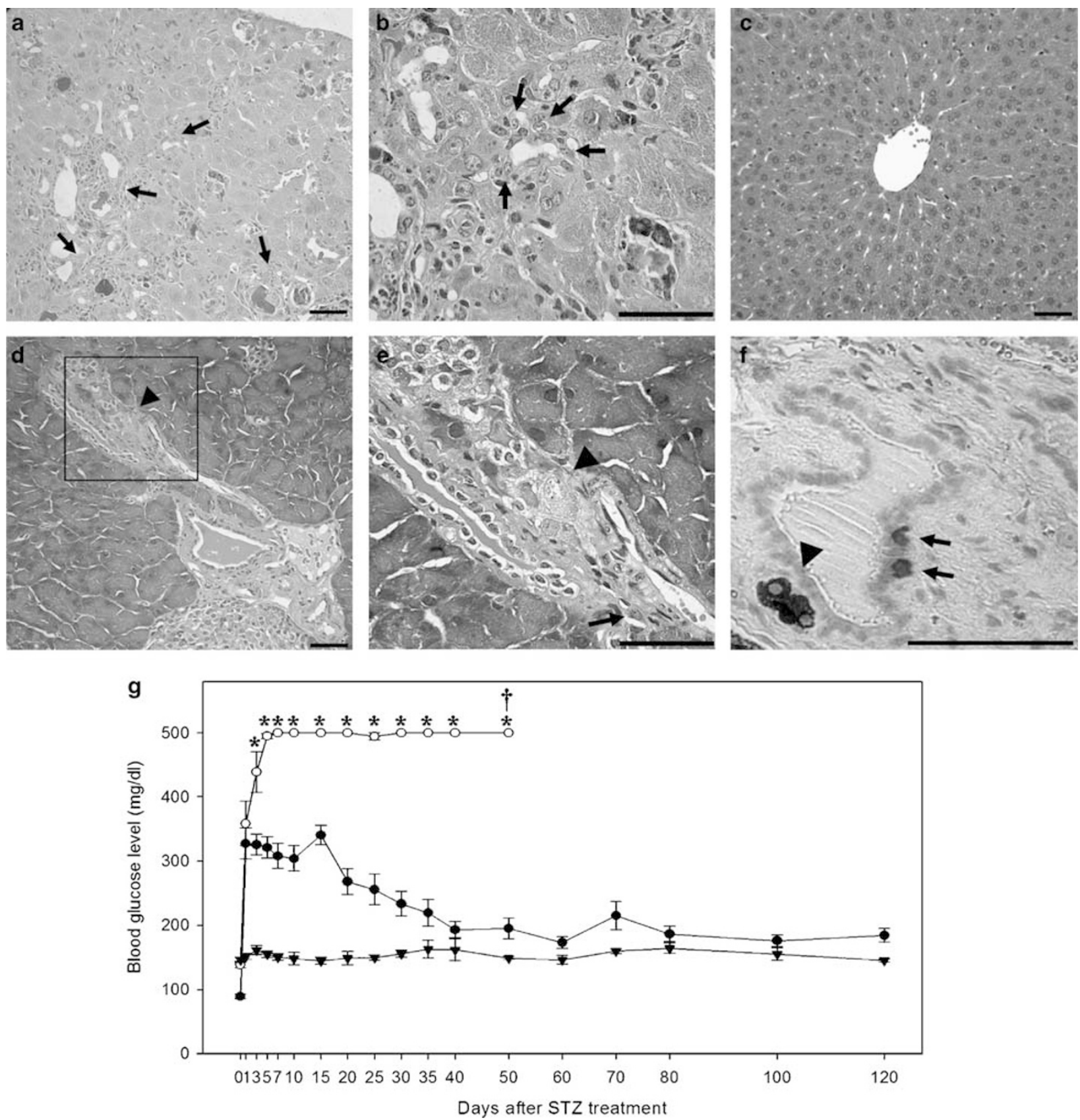

Figure 1 Histology of 4-week DDC-treated liver and pancreas and blood glucose level of DDC-STZ-treated mice. (a, b) Hematoxylin/eosin (H/E) staining of a representative 4-week DDC-treated liver. Hepatic oval cells (arrow) were at periductular junctions. (c) H/E staining of a normal liver. (d, e) H/E staining of 4-week DDC-treated pancreas. Pancreatic hepatocyte (arrow head) and possible oval/precursor cells (arrow) were observed near the main duct. The denoted oval cell was positive for insulin in serial cut sections (data not shown). (f) Double staining of insulin (arrow heads) and somatostatin (arrows) in DDC-treated pancreas at 14 days post-STZ injection. Bar $=100 \mu \mathrm{m}$. (g) STZ was injected intraperitoneally to normal and DDC-treated mice at Day 0. Blood glucose levels of DDC-STZ-treated mice (closed circles; $n=14$ ), normal mice (closed triangles; $n=5$ ) and STZ-treated mice (open circles; $n=10)$ were observed up to 120 days $\left({ }^{\dagger} P<0.005\right.$ vs DDC-STZ at 50 days). STZ-treated mice died within 51 days. ${ }^{*}$ Indicates one or more samples have blood glucose levels higher than glucometer detection limit ( $>500 \mathrm{mg} / \mathrm{dl})$. Each bar represents the mean \pm s.e.

such as Pax and Nkx genes, which are needed for late endocrine cell maturation, were expressed only during the hyperglycemic stage. In contrast, all endocrine hormones except glucagon, the key pancreatic developmental factors such as PDX-1, ISL1, NeuroD and NGN3 and the pancreatic exo- crine enzymes were still transcribed after the reversal of hyperglycemia. To validate the RT-PCR result, proinsulin and insulin antibodies were localized in the livers of DDC-STZ mice. The area of proinsulin and insulin-positive cells was in close proximity to the hepatic vein and heme breakdown 
a

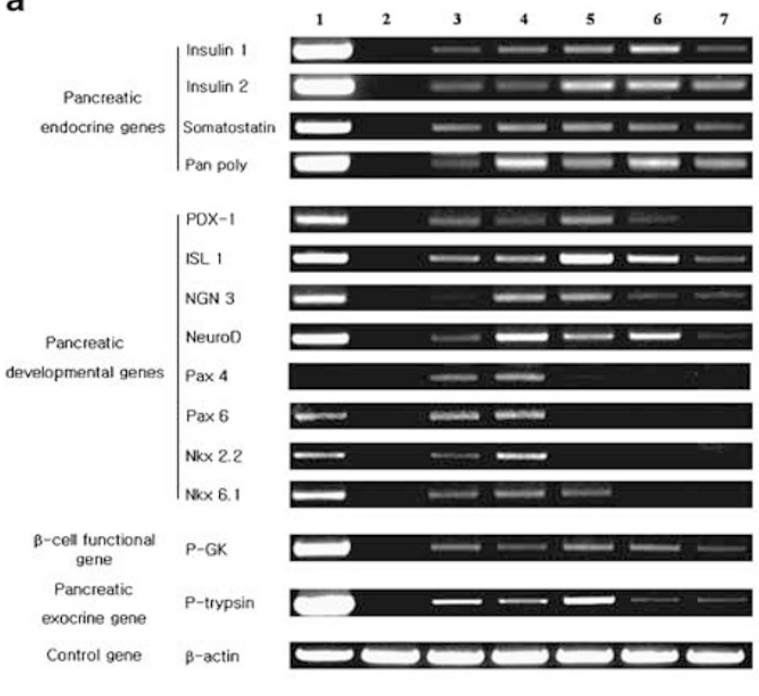

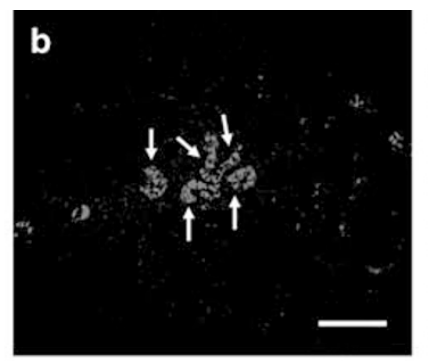
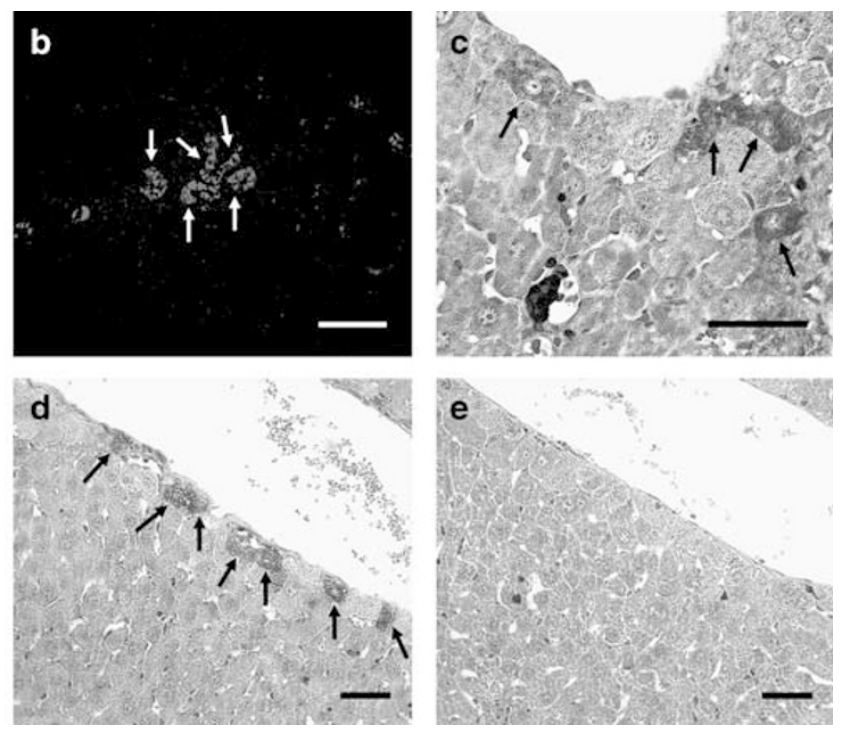

Figure 2 Transcription of pancreatic genes and immunohistochemistry of insulin in DDC-STZ-treated liver. (a) Representative RT-PCR data in DDC-STZtreated liver. Gene expression studies were performed with at least three separate samples, which showed similar data. Lane 1, representative normal pancreas; lane 2, 4-week DDC-treated liver; lane 3, DDC-treated liver at 5 days post-STZ injection; lane 4, DDC-treated liver at 15 days post-STZ injection; lane 5, DDC-treated liver at 30 days post-STZ injection; lane 6, DDC-treated liver at 60 days post-STZ injection; lane 7, DDC-treated liver at 120 days post-STZ injection. Pan poly, pancreatic polypeptide; P-trypsin, Pancreatic trypsin; P-GK, pancreatic glucokinase. (b) Proinsulin-positive cells in the DDC-treated liver at 7 days post-STZ injection. (c, d) Insulin-positive cells in the DDC-treated liver at 14 days post-STZ injection. (e) Serial cut section without the primary antibody served as a negative control. Bar $=100 \mu \mathrm{m}$.

debris, which coincides with the areas of hepatic oval cell activation (Figure $2 \mathrm{~b}-\mathrm{d}$ ). However, our random point calculation for insulin positive area in DDC-STZ-treated livers indicated that insulin-positive cells represented less than $1 \%$ of total cells in the animals that had restored blood glucose level (data not shown).

\section{Changes of Pancreas Endocrine Cell Population in DDC-STZ-Treated Mice}

On the basis of our observations in the liver, we inferred that regeneration of the pancreas would be required to explain the decrease of blood glucose level in DDC-STZ-treated mice. To assess this, we next performed immunohistochemistry of DDC-STZ-treated pancreata at various time points. The DDC-STZ-treated pancreas was characterized by the presence of single insulin-positive cells and the increase of smaller islets. Many of these insulin-positive cells were located near ducts (Figure 3a-f). By contrast, insulin-positive ductal cells were rarely found in normal and STZ-treated pancreas (Figure $4 \mathrm{a}$ ). The islet size analysis confirmed the distinct increase of neoislet population ( $<50 \mu \mathrm{m}$ in diameter) during the restoration of normal blood glucose level (Figure 4c), which is also observed in other pancreas regeneration models. $^{23}$

Regenerated Pancreas and Aberrant Islet Morphology In a previous study, Fernandes et $a l^{24}$ proposed that newly formed primitive $\beta$-cells coexpress somatostatin and insulin. To determine whether expanded $\beta$-cells in our model are the consequence of $\beta$-cell regeneration, we performed double immunofluorescence microscopy using anti-insulin and antisomatostatin antibodies. We could detect insulin-somatostatin double-positive cells in pancreas at 14 days post-STZ injection (Figure 5a-c). However, few insulin-positive cells coexpressed somatostatin at 42 days post-STZ injection (Figure 5d-f). The insulin-somatostatin-positive cells were also observed in residual islet cells (Figure $5 \mathrm{~g}-\mathrm{i}$ ). Double immunostaining for insulin-glucagon or insulin-somatostatin indicated that the endocrine cells of early stage in regeneration displayed more scattered and disorganized patterns (Figure 6). The islets of the restored blood glucose level in DDC-STZ-treated pancreas did not possess the morphology of normal mature islets.

\section{Proportion of Hepatic and Pancreatic Insulin in DDC-STZ-Treated Mice}

To determine the contribution of hepatic and pancreatic insulin, we analyzed the content of immunoreactive insulin in each organ (Table 1). Livers from mice at 14 days after STZ injection contained approximately 10 times more immunoreactive insulin per gram tissue than livers from normal mice did. In addition to the gram-per-tissue insulin content comparison, total insulin contents in both organs were calculated as the liver is a much larger organ than the pancreas. Even though insulin production per gram tissue was low in the liver, the total hepatic insulin was $43 \%$ compared to the pancreatic insulin at 14 days post-STZ injection, which overlaps with the expression of major 

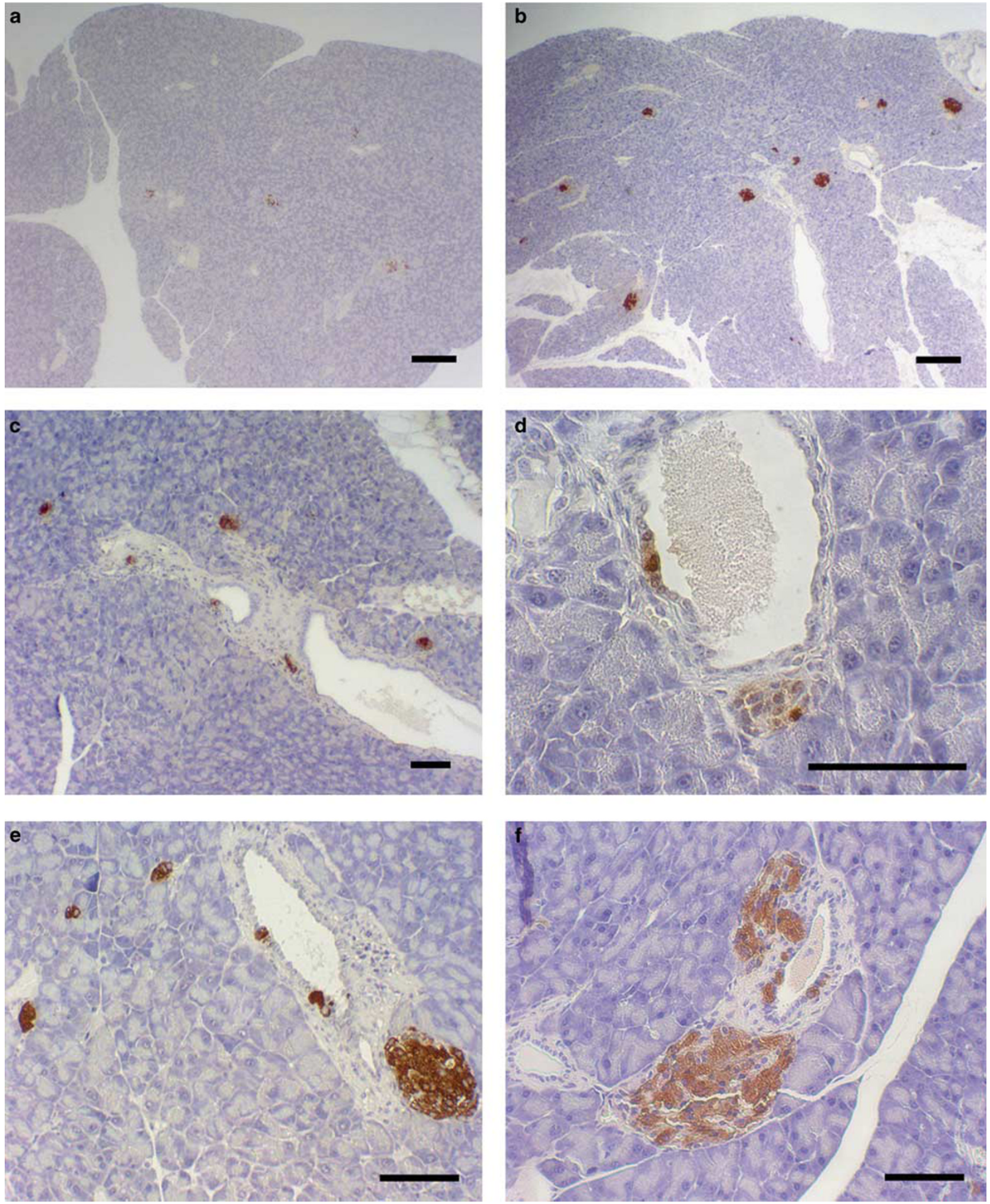

Figure 3 Immunostaining of insulin and analysis of DDC-STZ-treated pancreas. (a, b) Low magnification $(\times 40)$ of representative DDC-treated pancreata 3 and 63 days post-STZ injection, respectively. Insulin-positive cells were stained with DAB (brown). Bar $=200 \mu \mathrm{m}$. (c, d) DDC-treated pancreata 14 days postSTZ injection. Most of large islet $\beta$-cells were destroyed. Increased number of small $\beta$-cell cluster and single $\beta$-cells near ducts were observed. Bar $=75 \mu \mathrm{m}$. (e, f) DDC-treated pancreata 35 and 63 days post-STZ injection, respectively. Note the increase of ductal insulin-positive cells, which were rarely found in normal pancreas. Small $\beta$-cell cluster and single $\beta$-cells were common at various time points. $\mathrm{Bar}=75 \mu \mathrm{m}$. 

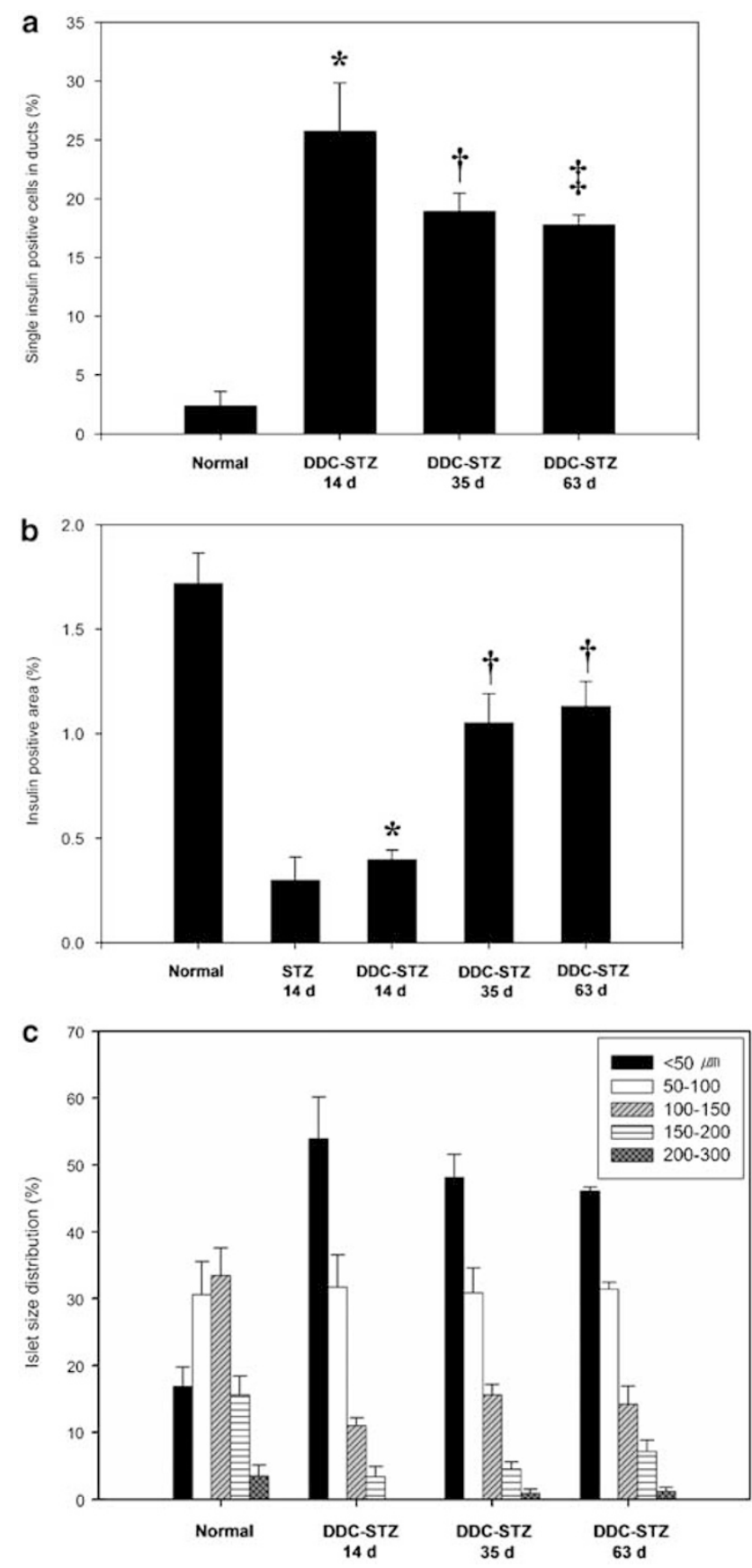

Figure 4 Statistical analysis of pancreas regeneration. (a) The number of single insulin-positive cells associated with ducts was divided by the total single insulin-positive cells observed in DDC-STZ-treated pancreata. Single insulin-positive cells associated with ducts were significantly increased $\left({ }^{\star} P=0.0001 ;{ }^{\dagger} P=0.0017 ;{ }^{\ddagger} P=0.0032\right.$ vs normal pancreata). (b) Insulin positive area at 14 days post-STZ injection was significantly reduced ( ${ }^{\star} P 0.001$ vs normal pancreas). Nonetheless, the area was gradually increased ( ${ }^{\top} P<0.005$ vs DDC-STZ 14 d). (c) The proportion of small pancreatic islets was markedly increased as the $\beta$-cell regeneration occurred. Each bar represents the mean \pm s.e.

pancreatic transcription factors including Pax and Nkx genes (Figure 2a). Such notable hepatic insulin increase and contribution were not observed in STZ-treated control. Hepatic insulin production was gradually decreased after the reversal of hyperglycemia, which is consistent with the results of RTPCR and immunohistochemistry of DDC-STZ-treated liver (Figure 2). Whereas pancreatic insulin content was significantly decreased after the initial STZ injection, the level of insulin was recovered to $33 \%$ of the normal control group by 63 days post-STZ injection, which is in accordance with Figure 4. Glucose-tolerance tests supported the ELISA data as fasting glycemia and glucose-tolerance were mildly impaired in DDC-STZ-treated mice and improved by time. The DDCSTZ-treated mice had significantly lower fasting glucose level and showed better glucose tolerance compared to STZ-treated mice during the initial hyperglycemia stage (Figure 7a). The glucose-tolerance ability of DDC-STZ mice was gradually enhanced throughout the follow-up period (Figure $7 \mathrm{~b}$ ).

\section{DISCUSSION}

The possibility of hepatic insulin-producing cells in diabetic mice was previously predicted, but they did not contribute to the amelioration of hyperglycemia. ${ }^{8}$ In this study, we have demonstrated that the oval-cell-activated livers transcribed major pancreatic mRNAs and readily produced significant amount of insulin during the hyperglycemic stage. It has been reported that amelioration of hyperglycemia such as insulin supplementation after STZ injection could accelerate the regeneration of $\beta$-cells. ${ }^{9,22}$ In DDC-STZ-treated mice, we observed 10 -fold increase of the hepatic insulin content per gram tissue, which is $43 \%$ of total pancreatic insulin at 14 days after STZ treatment (Table 1). Considering that the blood glucose level was highest and the pancreata damaged by STZ had the lowest insulin contents at that time, the hepatic cells are thought to prevent excessive hyperglycemia, which would irreversibly damage the islet $\beta$-cells. ${ }^{25}$ Interestingly, hyperglycemia appears to be a critical environmental cue for hepatic oval cell transdifferentiation, ${ }^{10}$ as most pancreatic developmental and hormone genes were turned on at the peak of blood glucose level and insulin-positive cells were most frequently observed during the hyperglycemic phase (Figure 2). Hepatic insulin production was decreased after the reversal of hyperglycemia (Table 1). It is not certain whether the lineage restriction process after liver regeneration or turnaround of blood glucose level triggered it, but many transdifferentiated cells lose their ability to produce insulin in different culture condition in vitro., ${ }^{3,11,26}$ Transiently expressed genes such as Pax4, Pax6, Nkx 2.2 and Nkx 6.1 support the idea that hepatic cells actively transdifferentiate only during the hyperglycemic stage (Figure 2 ).

It is interesting that extensive pancreatic $\beta$-cell regeneration was observed after the peak of hepatic insulin production in DDC-STZ-treated mice (Figures 3 and 4 and Table 1). Our findings indicate that pancreas regeneration is the primary mechanism to explain the reversal of hyperglycemia. There are three known pathways for $\beta$-cell regeneration: islet $\beta$-cell replication, ductal precursor differentiation and transdifferentiation from non- $\beta$-cells in islets. It is known 

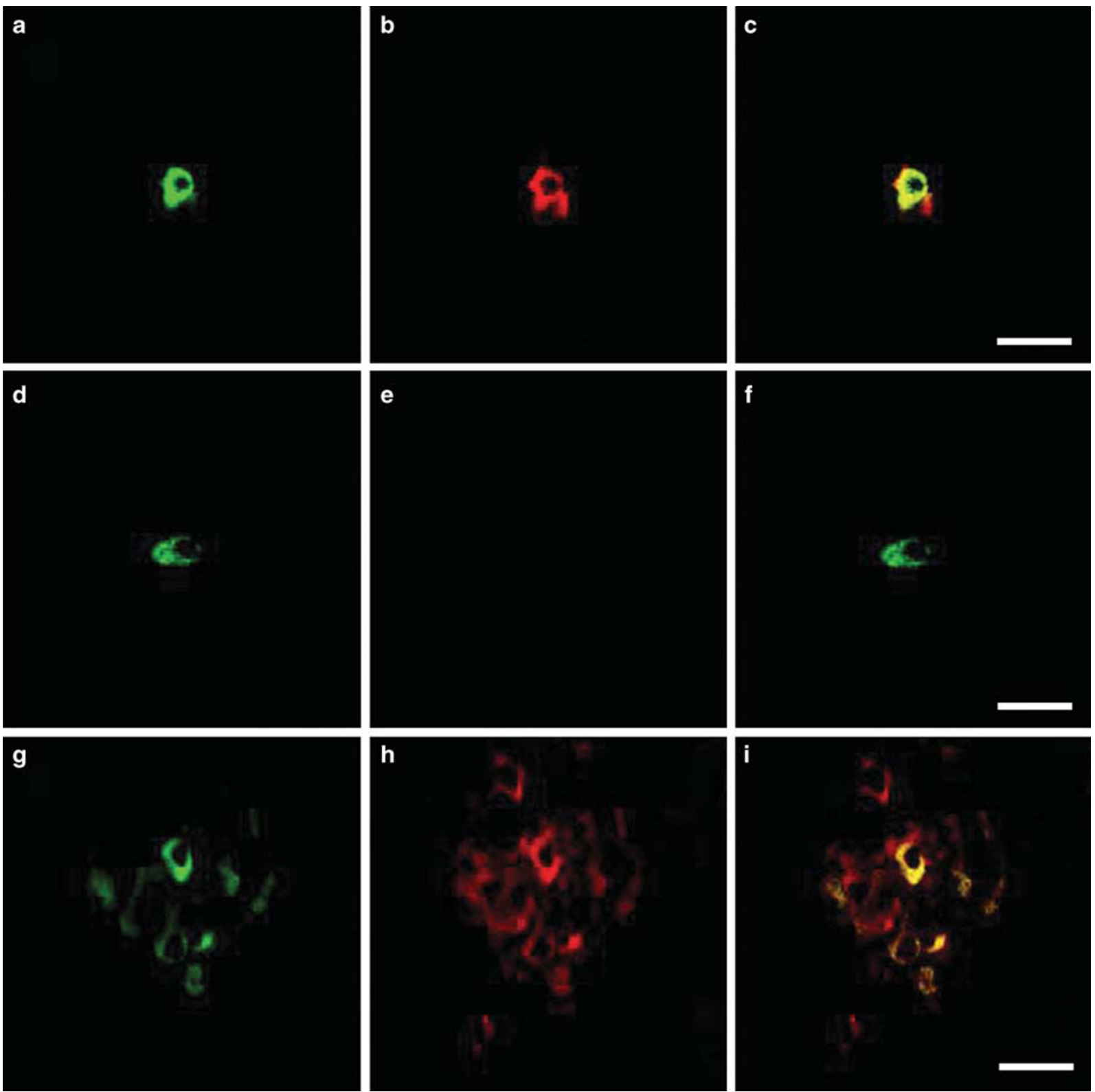

Figure 5 Colocalization of insulin and somatostatin in DDC-treated pancreas. Although STZ deteriorated most $\beta$-cells in mature islets, increased number of single insulin-positive cells (green; a, d) were observed. Approximately $35 \%$ of single insulin-positive cells coexpressed somatostatin (red) at 14 days post-STZ injection (a-c). The double-positive cells were less than $5 \%$ at 42 days post-STZ injection (d-f). Few single insulin-positive cells coexpressed somatostatin in the normal pancreas. A number of islet $\beta$-cells that weakly maintained expression of insulin at 14 days post-STZ treatment also coexpressed somatostatin, which suggests the $\beta$-cell regeneration in islets $(\mathbf{g}-\mathbf{i})$. $\operatorname{Bar}=20 \mu \mathrm{m}$.

that the neogenesis of islets from pancreatic duct epithelial cells occurs during normal embryonic development and in very early postnatal life. ${ }^{27}$ During the rest of adult life, endocrine cells can rarely be observed in mouse pancreatic ducts. ${ }^{6,28}$ Even though it is still controversial whether pancreas regeneration starts from the pancreatic duct epithelial cells or inner islet cells, ${ }^{29}$ various models using pancreatectomy, ${ }^{30,31}$ cellophane wrapping, ${ }^{32}$ duct ligation ${ }^{33}$ and IFN$\gamma$ transgenic mice ${ }^{28}$ have shown that ductal insulin-positive cells reappear which is considered to be a recapitulation of the embryonic events. In our model, up to $26 \%$ of total single insulin-positive cells were located in the ductal cell population, whereas less than $2 \%$ of single insulin-positive cells were observed in the normal pancreatic ducts (Figure 4). In addition, adjacent to the duct was the location of most of the regenerated islets, which suggests that islet neogenesis and regeneration originated from the precursor cells in pancreatic ducts (Figures 1 and 3).

It is of particular interest that the DDC-STZ-treated pancreas has a remarkable regenerative capacity. The recovery 

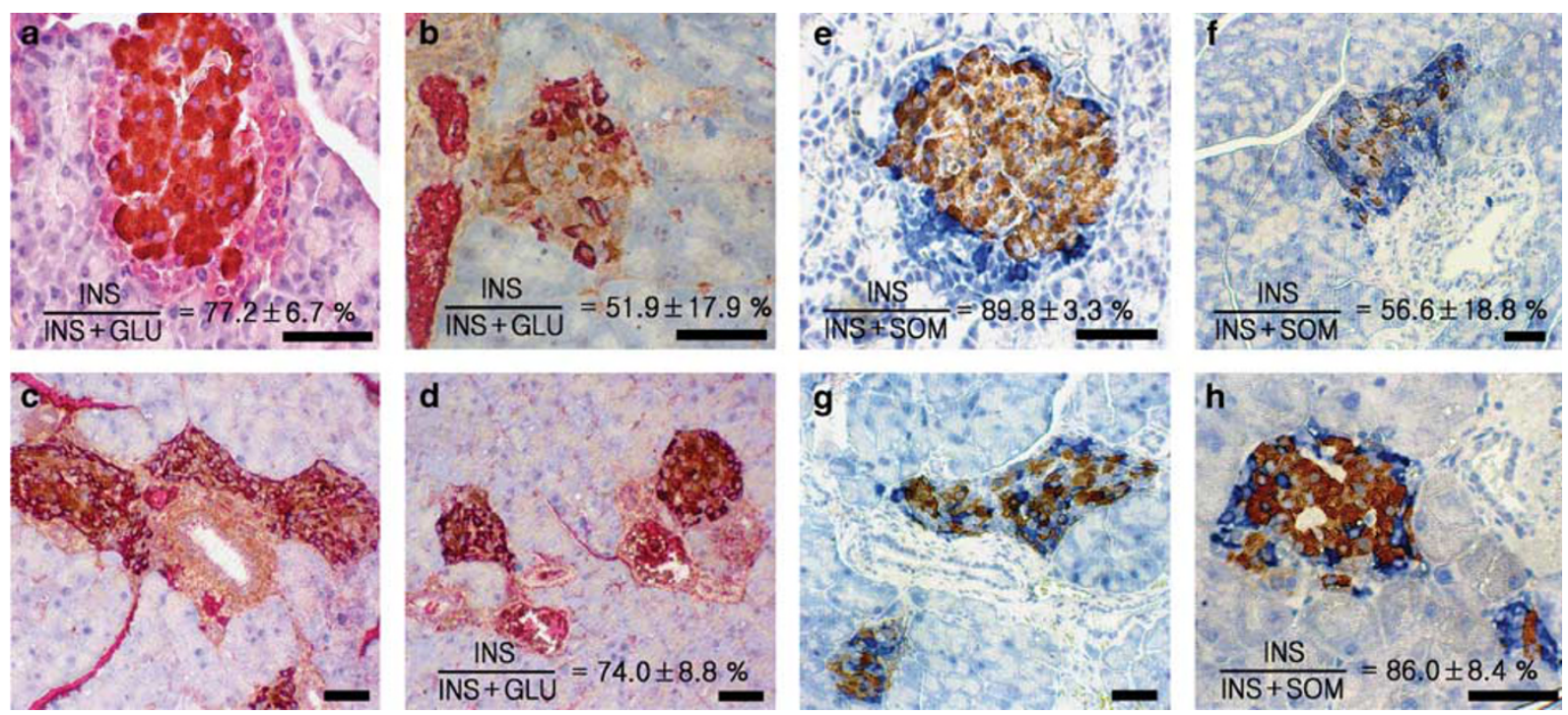

Figure 6 Immunohistochemical double staining of insulin, glucagon and somatostatin in DDC-STZ-treated pancreas. The glucagons-producing $\alpha$-cells (red or pink) are arranged peripheral to core $\beta$-cells (brown) in normal islets (a). The number of $\beta$-cells was significantly reduced at 14 days post-STZ injection (b). Slides taken at 35 and 63 days post-STZ injection respectively demonstrate that $\beta$-cells are regenerated, but islet morphology is aberrant compared to normal islets (c, d). The insulin producing $\beta$-cells (brown) are encompassed with somatostatin-producing $\delta$-cells (blue) in normal islets (e). $\beta$-Cells were markedly decreased at 14 days post-STZ injection (f). Islets at 35 and 63 days post-STZ injection respectively indicate $\beta$-cells were regenerated although the morphological difference still remained $(\mathbf{g}, \mathbf{h})$. Slides were counterstained with hematoxylin. INS, insulin-positive cells; GLU, glucagon-positive cells; SOM, somatostatin-positive cells. Bar $=50 \mu \mathrm{m}$.

Table 1 Quantitative analysis of hepatic and pancreatic insulin in DDC-STZ-treated mice

\begin{tabular}{lcccccccc}
\hline & Normal & DDC & $\begin{array}{c}\text { STZ } \\
(14 \text { days })\end{array}$ & $\begin{array}{c}\text { STZ } \\
(42 \text { days })\end{array}$ & $\begin{array}{c}\text { DDC-STZ } \\
(14 \text { days })\end{array}$ & $\begin{array}{c}\text { DDC-STZ } \\
(42 \text { days })\end{array}$ & $\begin{array}{c}\text { DDC-STZ } \\
(63 \text { days })\end{array}$ & $\begin{array}{c}\text { DDC-STZ } \\
(126 \text { days })\end{array}$ \\
\hline $\begin{array}{l}\text { Hepatic insulin } \\
\text { ( } \mu \text { g/g liver) }\end{array}$ & $0.046 \pm 0.012$ & $0.059 \pm 0.022$ & $0.068 \pm 0.027$ & $0.063 \pm 0.021$ & $0.445 \pm 0.126^{*}$ & $0.159 \pm 0.024$ & $0.189 \pm 0.019$ & $0.150 \pm 0.019$ \\
$\begin{array}{l}\text { Pancreatic insulin } \\
(\mu \mathrm{g} / \mathrm{g} \text { pancreas) }\end{array}$ & $84.9 \pm 0.5$ & $55.4 \pm 6.9$ & $4.1 \pm 0.7$ & $2.0 \pm 0.4$ & $8.1 \pm 1.2$ & $25.8 \pm 2.6^{* *}$ & $27.9 \pm 5.7^{* *}$ & $26.2 \pm 0.5^{* *}$ \\
Hepatic/pancreatic insulin (\%) ${ }^{\mathrm{a}}$ & $0.3 \pm 0.1$ & $0.4 \pm 0.1$ & $10.2 \pm 4.7$ & $19.9 \pm 7.3$ & $43.1 \pm 8.9$ & $4.7 \pm 0.2$ & $6.0 \pm 2.2$ & $3.5 \pm 0.4$
\end{tabular}

Immunoreactive insulin content in the extract of each organ was quantified along different time periods $(n=5$ for DDC-STZ at 14 days and $n=3$ for other samples). Insulin levels were measured and normalized to the wet weight of the homogenized tissue. Despite the rapid decline of pancreatic insulin content at 14 days post-STZ injection, hepatic insulin was significantly increased up to 10 times ( ${ }^{*}<0.05$ vs normal liver). The insulin content of pancreas was significantly reduced by STZ damage, but gradually recovered up to $33 \%$ compared to the normal pancreas ( $* * P<0.01$ vs DDC-STZ at 14 days). Each represents the mean \pm s.e. ${ }^{a}$ The ratio of hepatic to pancreatic insulin contents was calculated from the total insulin in each organ by multiplying the total weight by the insulin content per gram tissue.

of adult pancreatic islet cells after STZ treatment is very limited even when normoglycemia is achieved by islet transplantation or insulin administration. ${ }^{22}$ The DDC-STZ treatment provides a useful model to investigate the longterm replenishment process of depleted $\beta$-cells in damaged adult pancreas. The other benefit of this model is that it does not require any surgery ${ }^{30,32,33}$ or transgenic mice, ${ }^{28}$ to observe extensive pancreatic $\beta$-cell regeneration in vivo. However, there is an arguable finding that DDC-treated mice suffer from mild hypoglycemia. It is reported that Mallory bodies, which are morphologic hallmarks of alcoholic stea- tohepatitis, are also induced by intoxication with DDC. ${ }^{13,34}$ Such metabolic injury may explain the hypoglycemia, as chronic liver diseases normally alter several glucose metabolisms. ${ }^{35}$ It should also be considered that several inducers of Mallory bodies including DDC are also inducers of free radicals. Decrease of pancreatic insulin content in DDCtreated pancreas suggests that DDC is rather an oxidative stress initiator than a potential insulinotropic agent, which makes this model distinct from GLP-1/Exendin- 4 model. ${ }^{36}$

Hepatic insulin production by pancreatic gene transfection is one of the major approaches to the future treatment of 

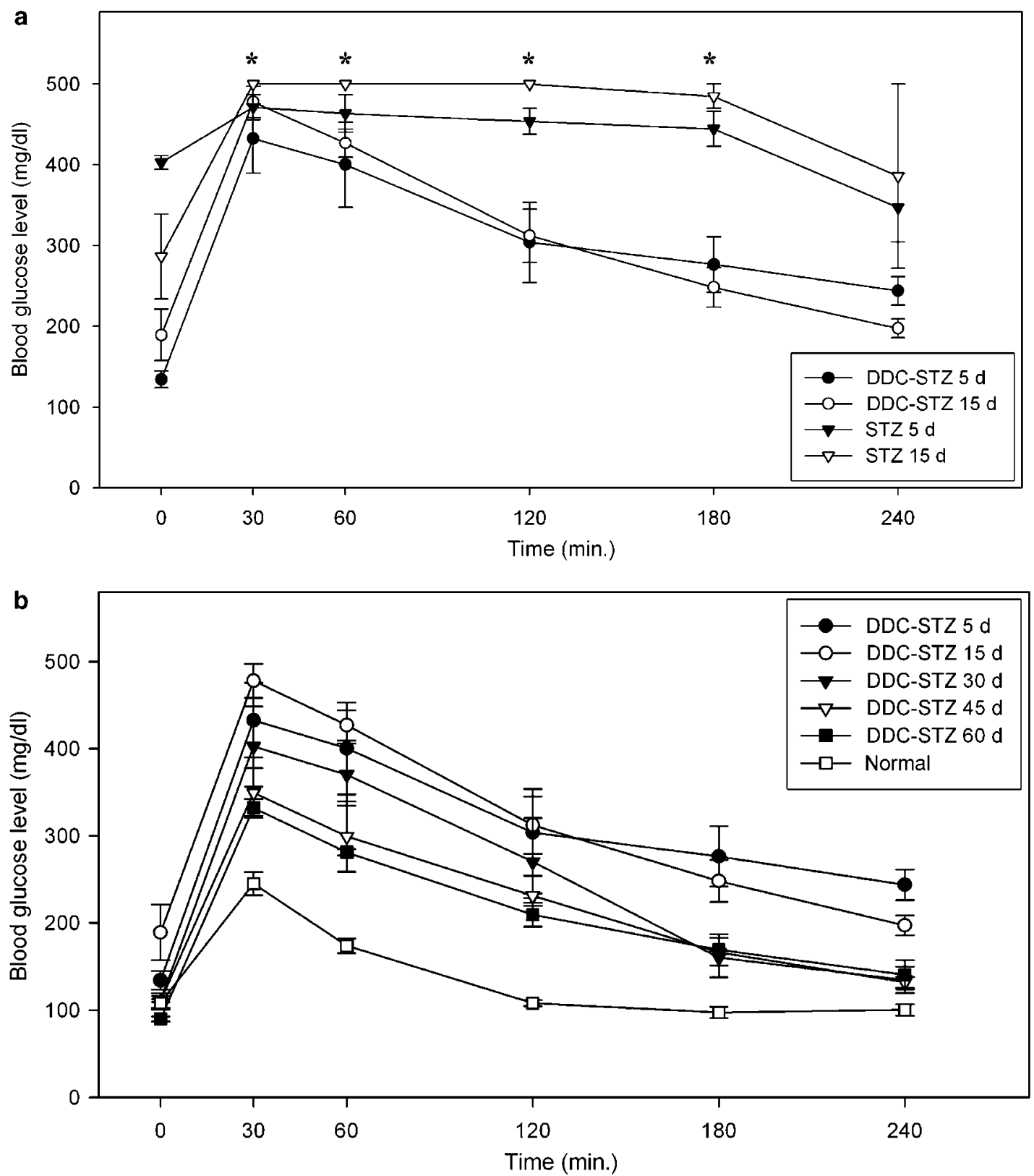

Figure 7 Intraperitoneal glucose-tolerance tests for DDC-STZ-treated mice. Glucose tolerance between DDC-STZ and STZ groups showed that The DDC-STZ-treated mice had significantly lower fasting glucose level with better glucose tolerance compared to STZ-treated mice (a). Glucose tolerance of DDC-STZ-treated mice was gradually improved (b). Same animals for DDC-STZ $(n=3)$, STZ $(n=3)$ and normal $(n=5)$ groups were measured throughout the experiment to follow the improvement of glucose responses. *Indicates one or more samples have blood glucose levels higher than glucometer detection limit $(>500 \mathrm{mg} / \mathrm{dl})$. Each bar represents the mean \pm s.e.

diabetic patients. ${ }^{15}$ Our results suggest that such a goal can also be achieved by hepatic oval cell activation combined with hyperglycemia. We also have demonstrated that the reversal of hyperglycemia in our model is achieved by two steps: (1) active hepatic transdifferentiation during hyperglycemic stage, which initiates the recovery process; (2) extensive pancreatic $\beta$-cell regeneration stimulated by DDC treatment, which sustains the recovery process and maintain homeostatic blood glucose level. Further studies are needed to elucidate such sequential cooperative reestablishment of normoglycemia, which may result from the combined stem and progenitor cell activity in both organs. Lastly, the DDC-STZ-treated pancreas, which has a remarkable ability to replenish damaged islets, provides a new model for understanding $\beta$-cell differentiation and pancreatic islet regeneration in vivo.

Supplementary Information accompanies the paper on the Laboratory Investigation website (http://www.laboratoryinvestigation.org) 


\section{ACKNOWLEDGEMENT}

This study was supported by a grant from Korea Food and Drug Administration (03092-073). SK and M-JL held Brain Korea 21 fellowships from Korea Ministry of Education and Human Resources Development.

1. Hellestrom C. Growth pattern of pancreatic islets in animals. In: Volk BV, Wellman KE (eds). The diabetic pancreas, 1st edn. Plenum Medical Book Co: New York, 1977, pp 61-97.

2. Shapiro AM, Ricordi $C$, Hering $B J$, et al. International trial of the Edmonton protocol for islet transplantation. N Engl J Med 2006;355:1318-1330.

3. Ramiya VK, Maraist M, Arfors $\mathrm{KE}$, et al. Reversal of insulin-dependent diabetes using islets generated in vitro from pancreatic stem cells. Nat Med 2000:6:278-282.

4. Bonner-Weir S, Taneja M, Weir GC, et al. In vitro cultivation of human islets from expanded ductal tissue. Proc Natl Acad Sci USA 2000;97:7999-8004.

5. Zulewski H, Abraham EJ, Gerlach MJ, et al. Multipotential nestinpositive stem cells isolated from adult pancreatic islets differentiate ex vivo into pancreatic endocrine, exocrine, and hepatic phenotypes. Diabetes 2001:50:521-533.

6. Teta M, Long SY, Wartschow LM, et al. Very slow turnover of beta cells in aged adult mice. Diabetes 2005;54:2557-2567.

7. Weir GC, Laybutt DR, Kaneto $H$, et al. Beta-cell adaptation and decompensation during the progression of diabetes. Diabetes 2001;50:S154-S159.

8. Kojima $\mathrm{H}$, Fujimiya $M$, Matsumura $\mathrm{K}$, et al. Extrapancreatic insulinproducing cells in multiple organs in diabetes. Proc Natl Acad Sci USA 2004;101:2458-2463.

9. Guz Y, Nasir I, Teitelman G. Regeneration of pancreatic beta cells from intra-islet precursor cells in an experimental model of diabetes. Endocrinology 2001;142:4956-4968.

10. Yang L, Li S, Hatch $\mathrm{H}$, et al. In vitro trans-differentiation of adult hepatic stem cells into pancreatic endocrine hormone-producing cells. Proc Natl Acad Sci USA 2002;99:8078-8083.

11. Tang $\mathrm{DQ}, \mathrm{Cao} \mathrm{LZ}$, Burkhardt $\mathrm{BR}$, et al. In vivo and in vitro characterization of insulin-producing cells obtained from murine bone marrow. Diabetes 2004:53:1721-1732.

12. Petersen BE, Zajac VF, Michalopoulos GK. Hepatic oval cell activation in response to injury following chemically induced periportal or pericentral damage in rat. Hepatology 1998;27:1030-1038.

13. Preisegger $\mathrm{KH}$, Factor VM, Fuchsbichler $\mathrm{A}$, et al. Atypical ductula proliferation and its inhibition by transforming growth factor beta 1 in the 3,5-diethoxycarbonyl-1,4-dihydrocollidine mouse model for chronic alcoholic liver disease. Lab Invest 1999;79:103-109.

14. Lammert E, Cleaver O, Melton D. Role of endothelial cells in early pancreas and liver development. Mech Dev 2003;120:59-64.

15. Meivar-Levy I, Ferber S. New organs from our own tissues: liver to pancreas transdifferentiation. Trends Endocrinol Metab 2003;14 460-466.

16. Grompe M. Pancreatic-hepatic switches in vivo. Mech Dev 2004;120:99-106.

17. Choi KS, Shin JS, Lee JJ, et al. In vitro trans-differentiation of rat mesenchymal cells into insulin-producing cells by rat pancreatic extract. Biochem Biophys Res Commun 2005;330:1299-1305.
18. Kim YS, Lee JJ, Shin JS, et al. Enhancement of mouse pancreatic regeneration and HIT-T15 cell proliferation with rat pancreatic extract. Biochem Biophys Res Commun 2003;309:528-532.

19. Petersen BE, Grossbard B, Hatch $\mathrm{H}$, et al. Mouse A6-positive hepatic oval cells also express several hematopoietic stem cell markers. Hepatology 2003;37:632-640.

20. Rao MS, Subbarao V, Reddy JK. Induction of hepatocytes in the pancreas of copper-depleted rats following copper repletion. Cell Differ 1986;18:109-117.

21. Reddy JK, Rao MS, Yeldandi AV, et al. Pancreatic hepatocytes, an in vivo model for cell lineage in pancreas of adult rat. Dig Dis Sci 1991;36: 502-509.

22. Bonner-Weir S, Sharma A. Pancreatic stem cells. J Pathol 2002;197: 519-526.

23. Risbud MV, Bhonde RR. Models of pancreatic regeneration in diabetes. Diabetes Res Clin Pract 2002;58:155-165.

24. Fernandes A, King LC, Guz Y, et al. Differentiation of new insulinproducing cells is induced by injury in adult pancreatic islets. Endocrinology 1997;138:1750-1762.

25. Dong $\mathrm{H}$, Altomonte J, Morral N, et al. Basal insulin gene expression significantly improves conventional insulin therapy in type 1 diabetic rats. Diabetes 2002:51:130-138.

26. Beattie GM, Itkin-Ansari $P$, Cirulli V, et al. Sustained proliferation of PDX-1+ cells derived from human islets. Diabetes 1999;48: 1013-1019.

27. Dubois PM. Ontogeny of the endocrine pancreas. Horm Res 1989;32:53-60

28. Gu D, Sarvetnick N. Epithelial cell proliferation and islet neogenesis in IFN-g transgenic mice. Development 1993;118:33-46.

29. Dor Y, Brown J, Martinez Ol, et al. Adult pancreatic beta cells are formed by self-duplication rather than stem-cell differentiation. Nature 2004:429:41-46.

30. Bonner-Weir S, Baxter LA, Schuppin GT, et al. A second pathway for regeneration of adult exocrine and endocrine pancreas. A possible recapitulation of embryonic development. Diabetes 2003;42: 1715-1720.

31. Shin JS, Lee JJ, Lee EJ, et al. Proteome analysis of rat pancreas induced by pancreatectomy. Biochem Biophys Acta 2005;1749: 23-32.

32. Rosenberg L, Duguid WP, Vinik Al. The effect of cellophane wrapping of the pancreas in the Syrian golden hamster: autoradiographic observations. Pancreas 1989;4:31-37.

33. Wang RN, Kloppel G, Bouwens L. Duct- to islet-cell differentiation and islet growth in the pancreas of duct-ligated adult rats. Diabetologia 1995;38:1405-1411.

34. Denk H, Stumptner C, Zatloukal K. Mallory bodies revisited. J Hepatol 2000;32:689-702.

35. Yamaguchi $M$, Kamimura S, Takada J, et al. Case report: insulin-like growth factor II expression in hepatocellular carcinoma with alcoholic liver fibrosis accompanied by hypoglycaemia. J Gastroenterol Hepatol 1998;13:47-51.

36. Xu G, Stoffers DA, Habener JF, et al. Exendin-4 stimulates both beta cell replication and neogenesis, resulting in increased beta cell mass and improved glucose tolerance in diabetic rats. Diabetes 1999;48: $2270-2276$. 